\title{
Pseudoipoparatiroidismo di tipo 1A: evidenza radiologica delle alterazioni appendicolari
}

\author{
Laura Mazoni $^{1} \cdot$ Matteo Apicella ${ }^{1} \cdot$ Filomena Cetani $^{2}$
}

Accettato: 17 giugno 2020 / Pubblicato online: 4 settembre 2020

(c) The Author(s) 2020

Lo pseudoipoparatiroidismo tipo 1A (PPHP-1A) è stato recentemente classificato secondo la nuova nomenclatura proposta dal EuroPHP network come inactivating PTH/PTHrP signaling disorder type 2 (iPPSD2) [1]. Tale disordine, dovuto a una mutazione inattivante del gene GNAS, si caratterizza per la presenza di ipocalcemia ed elevati valori di PTH secondari alla resistenza all'azione ormonale, cui possono associarsi altre resistenze ormonali (TSH, Calcitonina, GH$\mathrm{RH}$, e gonadotropine). Dal punto di vista fenotipico, i pazienti presentano un corteo clinico definito come osteodistrofia di Albright (AHO) che comprende segni quali brachidattilia, ossificazioni ectopiche sottocutanee, bassa statura, obesità, facies arrotondata e ritardo mentale [2].

Presentiamo il caso di una paziente di 40 anni che afferiva alla nostra Unità Operativa per PPHP-1A, diagnosticato all'età di 14 anni e da allora in trattamento con calcio e calcitriolo [3]. La diagnosi è stata confermata mediante l'analisi genetica che ha rilevato una mutazione a livello del sito di splicing dell'introne 1 del gene GNAS. Tale mutazione è stata rilevata anche nella madre non affetta da resistenza ormonale e compatibile con la diagnosi di pseudoipoparatiroidismo.

La paziente presentava, inoltre, resistenza alla calcitonina e al TSH e, al momento della valutazione, era in terapia con calcio, calcitriolo e L-tiroxina con discreto controllo di malattia in assenza di segni o sintomi riferibili ad ipocalcemia [calcio ione 1,17 mol/L (v.n. 1,13-1,32); PTH: 46 ng/dl (v.n. 8-40); TSH 4,35 mUI/ml (0,4-4); calcitonina $85 \mathrm{pg} / \mathrm{ml}$

$凶$ L. Mazoni

lauramazoni1@gmail.com

1 Scuola di Specializzazione in Endocrinologia e Malattie del Metabolismo, Università di Pisa, Pisa, Italia

2 Azienda Ospedaliero-Universitaria Pisana, Unità di Endocrinologia 2, Pisa, Italia

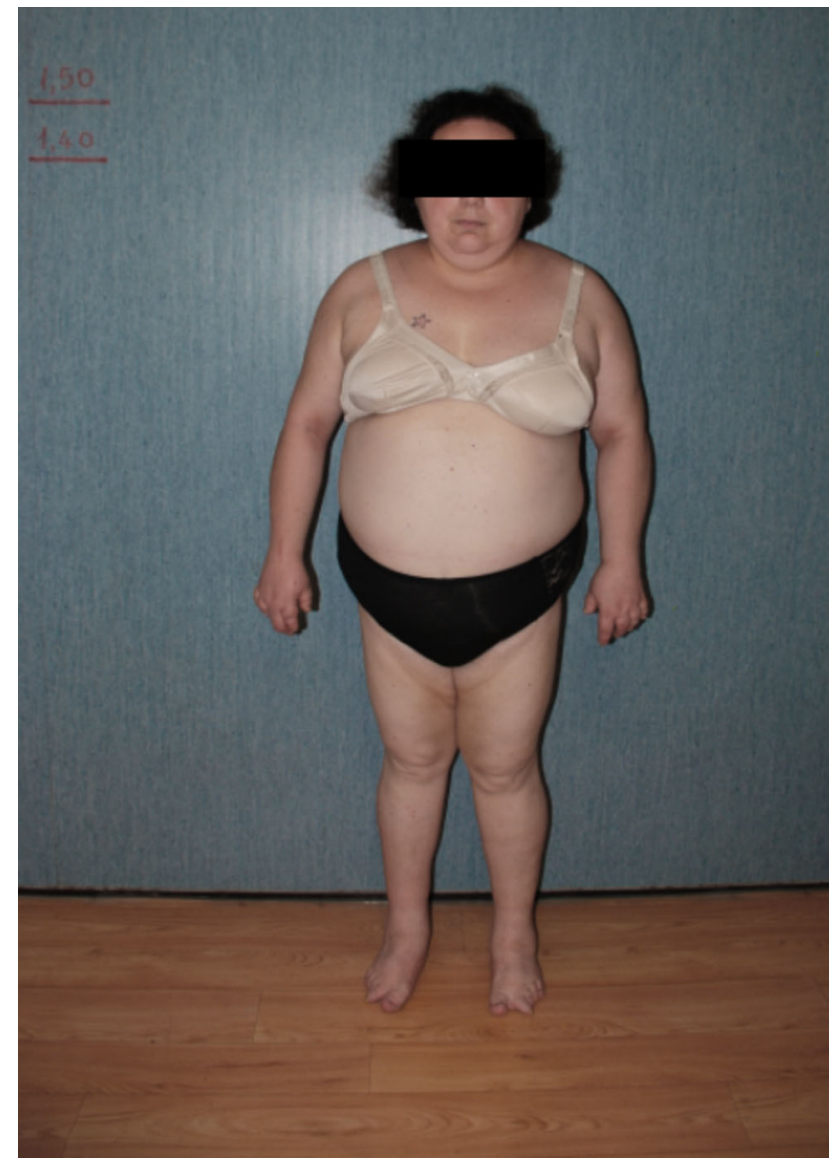

Fig. 1 Nell'immagine è possibile apprezzare le caratteristiche tipiche della $\mathrm{AHO}$, in particolare la bassa statura, l'obesità a prevalente distribuzione centrale, la facies arrotondata

(v.n. 11)]. La paziente era affetta da cardiopatia ischemica con pregressa ischemia miocardica acuta, asma bronchiale, ipertensione arteriosa e dislipidemia. 
Fig. 2 a Marcata brachidattilia di tipo E delle mani. Si evidenzia una diffusa brevità delle ossa metacarpali bilateralmente, soprattutto del I, IV e V metacarpo destro e del III, IV e V sinistro; b radiografia delle mani: il radiogramma conferma il quadro di brachidattilia bilaterale e mostra chiaramente la presenza di ossificazioni sottocutanee dei tessuti molli (frecce); c marcata brachidattilia dei piedi. $\mathrm{Si}$ evidenzia una diffusa brachidattilia con brevità delle ossa metatarsali bilateralmente, soprattutto del I, III, IV e V metacarpo; è presente inoltre un aspetto ricurvo del II dito e valgismo del I dito bilateralmente; $\mathbf{d}$ radiografia dei piedi: il radiogramma conferma il quadro della brachidattilia. A sinistra è evidente una marcata brevità della falange prossimale del I dito

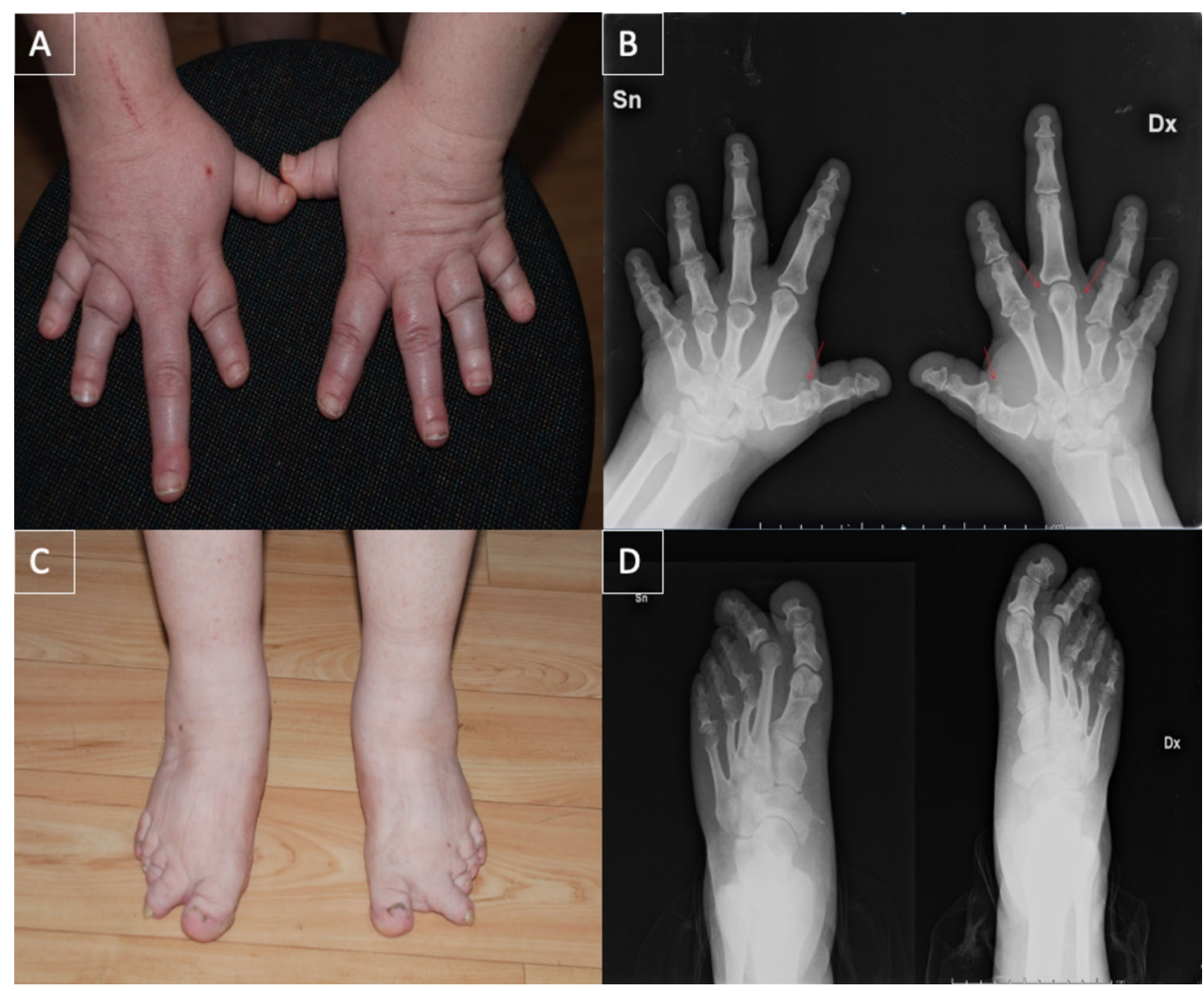

All'esame obbiettivo presentava segni evidenti di AHO: bassa statura, facies arrotondata, obesità (Fig. 1) e una marcata brachidattilia di tipo E (BDE) delle mani e dei piedi (Fig. 2).

Funding Note Open access funding provided by Università di Pisa within the CRUI-CARE Agreement.

Conflitto di interesse Gli autori Laura Mazoni, Matteo Apicella e Filomena Cetani dichiarano di non avere conflitti di interesse.

Consenso informato Lo studio presentato in questo articolo non ha richiesto sperimentazione umana. La paziente ha prestato il proprio consenso alla pubblicazione del caso e delle immagini.

Studi sugli animali Gli autori di questo articolo non hanno eseguito studi sugli animali.

Nota della casa editrice Springer Nature rimane neutrale in riguardo alle rivendicazioni giurisdizionali nelle mappe pubblicate e nelle affiliazioni istituzionali.

Open Access This article is licensed under a Creative Commons Attribution 4.0 International License, which permits use, sharing, adaptation, distribution and reproduction in any medium or format, as long as you give appropriate credit to the original author(s) and the source, provide a link to the Creative Commons licence, and indicate if changes were made. The images or other third party material in this article are included in the article's Creative Commons licence, unless indicated otherwise in a credit line to the material. If material is not included in the article's Creative Commons licence and your intended use is not permitted by statutory regulation or exceeds the permitted use, you will need to obtain permission directly from the copyright holder. To view a copy of this licence, visit http://creativecommons.org/licenses/by/4.0/.

\section{Bibliografia}

1. Thiele S, Mantovani G, Barlier A et al (2016) From pseudohypoparathyroidism to inactivating $\mathrm{PTH} / \mathrm{PTHrP}$ signalling disorder (iPPSD), a novel classification proposed by the EuroPHP network. Eur J Endocrinol 175(6):P1-17

2. Mantovani G, Bastepe M, Monk D et al (2018) Diagnosis and management of pseudohypoparathyroidism and related disorders: first international Consensus Statement. Nat Rev Endocrinol 14(8):476-500

3. Akkan T, Dagdeviren M, Koca AO et al (2020) Alternate-day calcium dosing may be an effective treatment option for chronic hypoparathyroidism. J Endocrinol Invest 43(6):853-858 